\title{
Disease patterns of pediatric non-Hodgkin lymphoma: A study from a developing area in Egypt
}

\author{
LAILA M. SHERIEF ${ }^{1,2}$, USAMA R. ELSAFY ${ }^{1}$, ELHAMY R. ABDELKHALEK ${ }^{1,2}$, \\ NAGLAA M. KAMAL ${ }^{3}$, DOAA M. YOUSSEF ${ }^{1}$ and RABAB ELBEHEDY ${ }^{1}$ \\ ${ }^{1}$ Department of Pediatrics, Faculty of Medicine, Zagazig University, Zagazig, Al Sharqiyah; \\ ${ }^{2}$ Benha Specialized Pediatric Hospital, Benha, Qalyubia; ${ }^{3}$ Department of Pediatrics, \\ Faculty of Medicine, Cairo University, Cairo, Egypt
}

Received July 29, 2014; Accepted September 5, 2014

DOI: $10.3892 / \mathrm{mco} .2014 .425$

\begin{abstract}
Non-Hodgkin lymphoma (NHL) accounts for 8-10\% of all childhood cancers. NHL collectively represents various lymphoid malignancies with diverse clinicopathological and biological characteristics. In this study, we aimed to describe the epidemiological and clinicopathological characteristics and treatment outcomes of pediatric NHL patients treated at the Pediatric Oncology Unit of Zagazig University Hospital and the Benha Specialized Pediatric Hospital. We conducted a cross-sectional retrospective study by reviewing the medical records of 142 patients admitted with a diagnosis of NHL over a period of 8 years (February, 2004 to February, 2012) in these two Oncology Units. The age at presentation ranged between 2 and 15 years, with a mean \pm standard deviation (SD) of $6.1 \pm 2.8$ years and a male:female ratio of 1.7:1. Abdominal involvement was the most common presentation (73.2\%). Burkitt's lymphoma (BL) was the most common NHL subtype (69\%), followed by lymphoblastic lymphoma, diffuse large B-cell lymphoma and anaplastic large-cell lymphoma, accounting for $18.3,10.6$ and $2.1 \%$ of the cases, respectively. The majority of the patients $(88.7 \%)$ had been diagnosed with advanced disease (Murphy stage III/IV). Complete remission was achieved in 120 cases $(84.5 \%)$. A total of 16 patients (11.3\%) succumbed to the disease during the first few months and 6 patients $(4.2 \%)$ remained alive following relapse. The mean follow-up duration \pm SD was 34.6 \pm 25.1 months (range, 3-84 months). The 5-year overall survival (OS) and event-free survival (EFS) rates were 88.7 and $85.1 \%$, respectively. None of the clinical, epidemiological or pathological variables exhibited a statistically significant association with the OS or EFS. In conclusion, NHL occurs at a younger age, with a higher incidence of BL and advanced-stage disease.
\end{abstract}

Correspondence to: Professor Laila M. Sherief, Department of Pediatrics, Faculty of Medicine, Zagazig University, 11 Osman Bin Affan Street, Al Gamaa Villas, Zagazig, Al Sharqiyah, Egypt

E-mail: lamesh25@yahoo.com

Key words: pediatrics, non-Hodgkin lymphoma, Egypt, disease patterns
The outcome of NHL in our two centers was satisfactory, approaching the international rates.

\section{Introduction}

Non-Hodgkin lymphoma (NHL) accounts for $8-10 \%$ of all childhood malignancies (1). NHL is a heterogeneous group of diseases, as malignant clonal proliferation may occur at any stage during lymphocyte proliferation. Four NHL subtypes comprise $90 \%$ of the NHL cases in children, namely Burkitt's lymphoma (BL), diffuse large B-cell lymphoma (DLBCL), lymphoblastic lymphoma (precursor T- and precursor B-cell lymphoma) and anaplastic large-cell lymphoma (ALCL) (2-5). The remaining $10 \%$ include marginal zone, cutaneous, follicular and peripheral T-cell lymphomas, which are the NHL subtypes common in the adult population (6-8). There has been a significant improvement in the overall survival (OS) of children and adolescents with NHL. The reported disease-free survival for pediatric NHL, independent of subtype, is currently $\sim 80 \%$ (3). The most significant prognostic determinants are type of treatment and the extent of the disease, as determined by pretreatment staging $(9,10)$. There is geographic variation in the incidence of NHL, particularly regarding BL, which is endemic in Equatorial Africa and accounts for $50 \%$ of all childhood cancers, affecting 50 children per million diagnoses (11). However, in other areas of the world, BL occurs sporadically and is less common, affecting 2 per million children (1). Depending on the geographic region investigated, there are major differences in terms of the clinical and epidemiological characteristics of NHLs diagnosed during childhood $(1,12)$. The scarcity of data available in the literature on the behavior of NHL among children in our region prompted us to conduct this study, with the aim of describing the clinical and epidemiological characteristics of NHL patients, assessing their survival and identifying possible prognostic associations with the variables under analysis.

\section{Patients and methods}

Patients and inclusion criteria. We retrospectively reviewed the records of children and adolescents with NHL treated consecutively between February, 2004 and February, 2012 at 
the Pediatric Oncology Unit of Zagazig University Hospital and the Benha Specialized Pediatric Hospital. The study was approved by the Research and Ethics Committees of the contributing hospitals. Patient records from the Pediatric Oncology Department containing oncological details on diagnosis, treatment course and follow-up were analyzed for this study. The inclusion criteria were as follows: i) children and adolescents aged $\leq 18$ years with pathologically confirmed NHL; ii) the diagnosis of NHL was established in all the cases by pathology in conjunction with immunophenotype studies and subclassified according to World Health Organization (WHO) criteria (13); and iii) all the anticancer treatments and follow-up examinations were completed at the abovementioned two centers. Disease staging was performed according to the St. Jude staging system (14).

Diagnosis and staging. Diagnostic investigations included biopsy of a clinically involved lymph node or mass, computed tomography (CT) scan of the chest, abdominopelvic ultrasonography and CT scan, bone marrow aspirates and biopsies and bone scintigraphy in selected cases. Diagnosis, staging and treatment planning for all the patients were performed by the center's multidisciplinary Pediatric Oncology Group. Laboratory tests included a complete blood count, liver and renal function tests, serum electrolyte, uric acid and lactate dehydrogenase levels and cerebrospinal fluid analysis. The clinical and laboratory findings evaluated for prognostic significance on event-free survival (EFS) and OS were age, gender, stage (I/II vs. III/IV) and pathology.

Treatment protocols. The therapeutic regimen was prescribed depending on histological type and immunophenotype of the lymphoma. BL and large B-cell lymphomas were treated with a chemotherapy protocol based on LMB-96. A therapeutic protocol based on modified CCG-1991 and CCG-1961 high-risk protocols was used for lymphoblastic lymphoma. A therapeutic protocol based on BFM-NHL 90 was used for ALCL. An ifosamide, caboblatin, etoposide (ICE) protocol was used for relapsed cases.

Statistical analysis. Data were statistically described as means \pm standard deviation (SD) and range, or frequencies (number of cases) and percentages where appropriate. A survival analysis was performed for the different outcome measures using Kaplan-Meier statistics, calculating the mean and median survival time for each group with their 95\% confidence intervals and corresponding survival graphs. $\mathrm{P}<0.05$ was considered to indicate a statistically significant difference. All the statistical calculations were performed using the Statistical Package for the Social Sciences software, version 15 (SPSS, Inc., Chicago, IL, USA) for Microsoft Windows.

\section{Results}

Patients. Between February, 2004 and February, 2012, 142 patients with NHL were admitted to our Pediatric Oncology Units. The age at presentation ranged between 2 and 15 years, with a mean \pm SD of $6.1 \pm 2.8$ years. The majority of the cases $(59.2 \%)$ of BL were diagnosed in children aged 2-5 years, followed by children aged 5-10 years (32.6\%); only $8.2 \%$ of the
Table I. Clinical and demographic characteristics of patients.

\begin{tabular}{|c|c|c|}
\hline \multirow{2}{*}{$\begin{array}{l}\text { Characteristics } \\
\text { Age (years) }\end{array}$} & \multicolumn{2}{|c|}{$\begin{array}{l}\text { Patient no. (\% } \\
\quad(n=142)\end{array}$} \\
\hline & & \\
\hline$<5$ & 58 & $(40.8)$ \\
\hline $5-10$ & 65 & $(45.8)$ \\
\hline$>10$ & 19 & $(13.4)$ \\
\hline \multicolumn{3}{|l|}{ Gender } \\
\hline Female & 52 & $(36.6)$ \\
\hline Male & 90 & $(63.4)$ \\
\hline \multicolumn{3}{|l|}{ Residence } \\
\hline Rural & 89 & $(62.7)$ \\
\hline Urban & 53 & $(37.3)$ \\
\hline \multicolumn{3}{|l|}{ Consanguinity } \\
\hline Positive & 33 & $(23.2)$ \\
\hline Negative & 109 & $(76.8)$ \\
\hline \multicolumn{3}{|l|}{ Histological type } \\
\hline Burkitt's lymphoma & 98 & $(69.0)$ \\
\hline Lymphoblastic lymphoma & 26 & $(18.3)$ \\
\hline Large-cell lymphoma & 15 & $(10.6)$ \\
\hline Anaplastic large-cell lymphoma & 3 & $(2.1)$ \\
\hline \multicolumn{3}{|l|}{ Primary site } \\
\hline Abdomen & 104 & $(73.2)$ \\
\hline Mediastinum & 23 & $(16.2)$ \\
\hline Peripheral lymph nodes & 9 & $(6.4)$ \\
\hline Other & 6 & $(4.2)$ \\
\hline \multicolumn{3}{|l|}{ Stage } \\
\hline I & 2 & $(1.4)$ \\
\hline II & 14 & $(9.9)$ \\
\hline III & 95 & $(66.9)$ \\
\hline IV & 31 & $(21.8)$ \\
\hline \multicolumn{3}{|l|}{ LDH (IU/dl) } \\
\hline$\leq 500$ & 41 & $(28.9)$ \\
\hline$>500$ & 101 & $(71.1)$ \\
\hline \multicolumn{3}{|l|}{ Protocol } \\
\hline LMB-96 & 113 & (79.6) \\
\hline CCG-1961 & 26 & $(18.3)$ \\
\hline BFM-NHL 90 & 3 & $(2.1)$ \\
\hline \multicolumn{3}{|l|}{ Outcome } \\
\hline Alive in CR & 120 & $(84.5)$ \\
\hline Alive following relapse & 6 & $(4.2)$ \\
\hline Deceased & 16 & $(11.3)$ \\
\hline
\end{tabular}

LDH, lactate dehydrogenase; CR, complete remission.

BL cases occurred in children aged $>10$ years. The majority of the patients with lymphoblastic lymphoma (78.6\%) were aged 5-10 years and only $14.2 \%$ were aged $<5$ years. However, all the cases of large-cell lymphoma were diagnosed at an age of $>5$ years, with $72.2 \%$ aged $5-10$ and $27.7 \%>10$ years. The NHL patient population included 90 male and 52 female patients (male:female ratio, 1.7:1). A total of 89 patients resided 


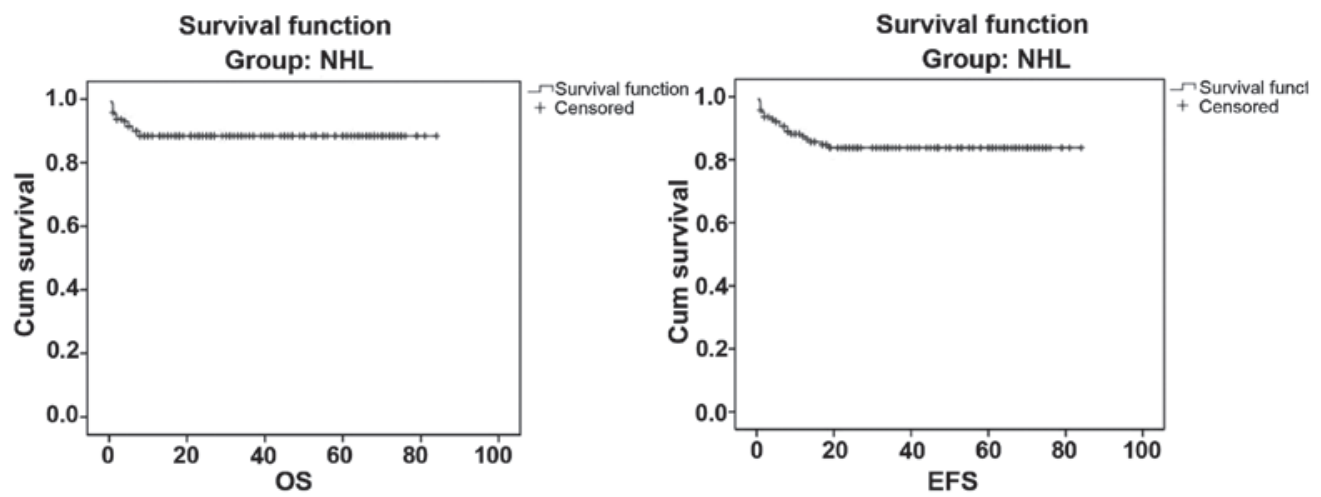

Figure 1. Five-year overall survival (OS) and event-free survival (EFS) of non-Hodgkin lymphoma (NHL).
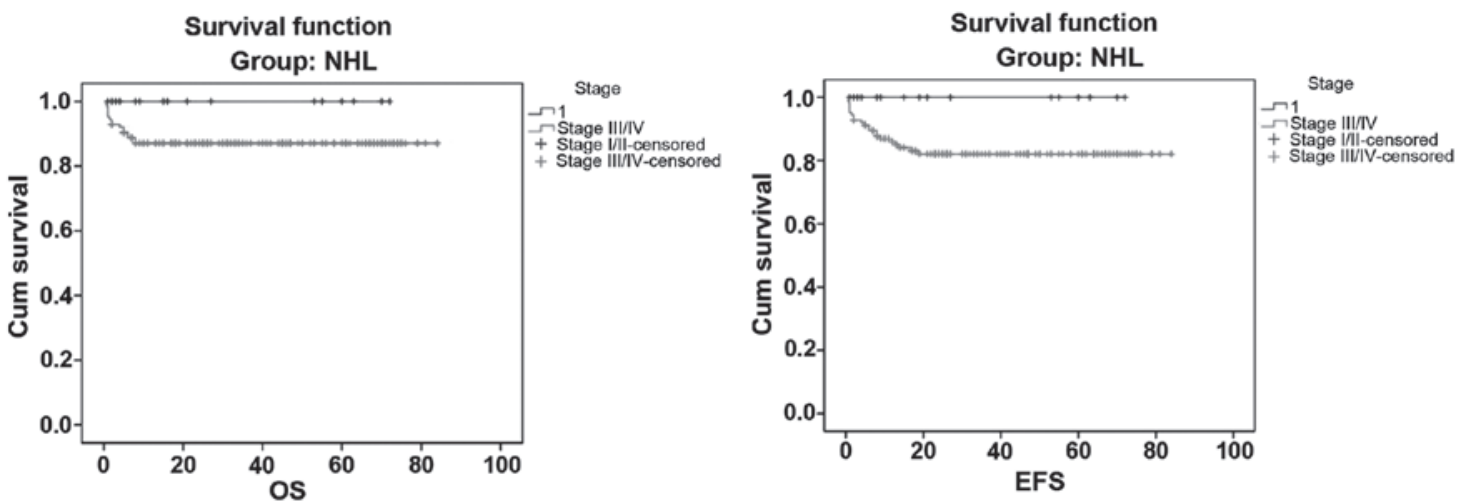

Figure 2. Five-year overall survival (OS) and event-free survival (EFS) according to stage. NHL, non-Hodgkin lymphoma.

Table II. Results of statistical tests for associations between overall survival and event-free survival and the study variables in non-Hodgkin lymphoma patients.

\begin{tabular}{lccccc}
\hline & \multicolumn{2}{c}{ Overall survival } & & \multicolumn{2}{c}{ Event-free survival } \\
\cline { 2 - 3 } \cline { 6 - 6 } Variables & Log-rank & P-value & & Log-rank & P-value \\
\hline Age & 0.71 & 0.70 & & 0.45 & 0.80 \\
Gender & 0.30 & 0.59 & & 1.78 & 0.18 \\
Pathology & 2.43 & 0.49 & & 3.02 & 0.39 \\
Stage & 1.94 & 0.16 & & 2.50 & 0.11 \\
\hline
\end{tabular}

in a rural and 53 in an urban area. A total of 33 patients $(23.2 \%)$ were born to consanguineous parents (Table I).

Types of NHL. Based on the WHO 2008 classification for hematolymphoid neoplasms (13), NHL was classified into two main groups, namely precursor and mature B- and T-cell hematolymphoid neoplasms.

Mature-cell NHL corresponded to $116(81.7 \%)$ of all NHL cases, including $113(79.6 \%) \mathrm{B}$ - and 3 (2.1\%) T-cell lymphomas. BL included 98 cases $(84.5 \%$ of all mature lymphomas and $86.7 \%$ of all mature B-cell lymphomas). BL is the most common NHL subtype, affecting 98 (69\%) of all NHL patients, followed by lymphoblastic lymphoma with 26 (18.3\%), DLBCL with 15 (10.6\%) and ALCL with 3 (2.1\%) patients (Table I).
Disease localization and staging. Primary abdominal tumors were the most common, affecting 104 (73.2\%) of our patients and bone marrow infiltration was the most common site of metastasis, affecting $31(21.8 \%)$ patients, followed by the central nervous system in $5(3.5 \%)$ and bone infiltration in 2 $(1.4 \%)$ patients.

Only $16(11.3 \%)$ patients had localized disease (stage I/II) and $126(88.7 \%)$ presented with advanced disease (stage III/IV). The majority of advanced-stage patients (95/126; 66.9\%), had stage III lymphoma. LMB-96 was the most used protocol, as BL and large-cell lymphoma predominated in our patients, accounting for $113(79.6 \%)$ of the cases (Table I).

Survival outcomes. The mean follow-up period \pm SD was 34.64 \pm 25.14 months (range, 3-84 months). A total of 126 patients achieved remission and 16 (11.3\%) patients succumbed to the disease. Death was attributed to tumor lysis syndrome in 2 and infection in 14 patients. Of the patients who achieved remission, 6 (4.2\%) developed a relapse, were treated and survived. The 5-year OS and EFS for all NHL cases were 88.7 and $85.1 \%$, respectively (Fig. 1). The 5-year OS and EFS for stage I/II cases were both $100 \%$, whereas for stage III/IV cases they were 87.3 and $83.2 \%$, respectively (Fig. 2). There was no statistically significant difference in the OS and EFS rates between the four stages (log-rank test, P>0.5; Table II). The 5-year OS and EFS for BL were 90.8 and $87.8 \%$, respectively, whereas for lymphoblastic lymphoma they were 80.7 and $80 \%$, respectively (Fig. 3). None of the clinical, epidemiological or pathological variables exhibited a statistically significant 

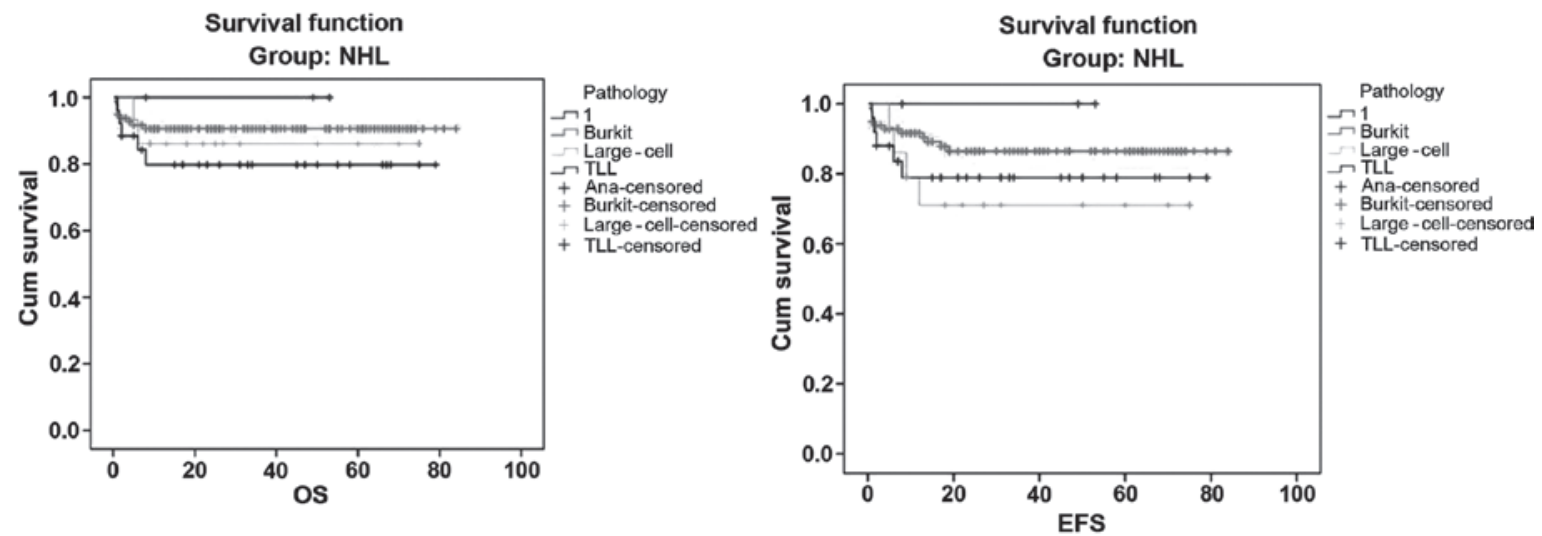

Figure 3. Five-year overall survival (OS) and event-free survival (EFS) of non-Hodgkin lymphoma (NHL) according to pathological subtypes. TLL, T-cell lymphoblastic lymphoma.

association with global survival or EFS, i.e., age, gender, stage and pathology were not significantly associated with patient outcome (P>0.05) (Table II).

\section{Discussion}

Lymphoma in children and adolescents comprises a heterogeneous group of malignant diseases of lymphoid tissues. The various lymphoma diagnoses present with distinctive biological and epidemiological characteristics. There are significant variations worldwide in the incidence of childhood malignancies, among which lymphomas are the dominant type (15). The present study describes the epidemiological and clinical characteristics of 142 Egyptian pediatric NHL patients admitted to two Pediatric Oncology Units. Patients aged $<10$ years consituted $>88.5 \%$ of our study sample and there was a trend toward a decrease of the relative incidence with increasing age, with 88.5 and $11.5 \%$ for the age groups of $0-10$ and $>10$ years, respectively, which was consistent with previously reported findings (16-18). Sandlund et al (1) and Manipadam et al (19) reported that the incidence of NHL increases uniformly with age and is rarely diagnosed before 2 years of age. The possibility of an infectious etiology, principally associated with Epstein-Barr virus (EBV) (12), being involved in the pathogenesis of NHL may be a partial explanation of the emergence of this disease in younger patients in our region, as populations of lower socioeconomic status are presumably exposed to infectious agents earlier in life. The incidence of childhood NHL was generally higher in male $(63.4 \%)$ compared to female $(36.6 \%)$ patients and this male predominance of childhood lymphoma mirrors the reported general pattern of male predominance exhibited by lymphoid malignancies, but not by all types of cancer $(16,18)$. Although the majority of lymphomas in adults are of low or intermediate grade, $>90 \%$ of childhood NHLs are of high grade and may be classified into one of four main categories (20).

BL was the most common NHL subtype (69\%) in our series. Furthermore, BL accounted for 78.2, 77.2, 68, 48.2, 42.2 and $39 \%$ of the cases in studies conducted in Brazil, Kuwait, Saudi Arabia, Germany, UK and Egypt, respectively (16,21-25). By contrast, BL was encountered at a surprisingly low frequency (9-12\%) in India, Pakistan and Shanghai $(21,26)$.
There is evidence that the incidence of BL varies markedly worldwide, being particularly high in Equatorial Africa, which is likely due to early infection by EBV (almost all cases in Africa are EBV-related) and chronic exposure to malaria. As early exposure to EBV is associated with a lower socioeconomic status and BL is commonly associated with EBV worldwide, the variability in the incidence of BL is likely to be, at least in large part, a function of the epidemiology of EBV (27).

Our analysis revealed that the proportion of precursor T-cell lymphoblastic lymphoma (TLL) was $18.3 \%$ of all NHLs, which is lower among children in Egypt compared to other Asian countries. The proportion of T-cell NHL is significantly higher in the Korean pediatric and young adult population (28), Japan (29) and India (19,26), while the frequency of TLL was found to be low in Saudi Arabia (8\%), Pakistan (8\%) and nearly the same results were obtained from the UK (19\%) and Germany $(16.1 \%)(23,24)$.

Overall, DLBCL accounted for $10.6 \%$ of all pediatric NHLs. This finding was similar to that reported in the English literature. Burkhardt et al (24) found that DLBCL constituted $13 \%$ of pediatric NHLs. Wright et al (23) reported that B-cell NHLs other than lymphoblastic lymphoma and BL constituted $7.8 \%$ of the cases and comprised centroblastic lymphoma, high-grade B-cell NHL not otherwise specified, T-cell-rich B-cell lymphoma and primary mediastinal large B-cell lymphoma. The frequency of DLBCL was higher in Korea (28) and Japan (29). Pediatric DLBCL is considered to be biologically different from its adult counterpart and is associated with an excellent prognosis. In this study, ALCL was the fourth most common NHL subtype and constituted only $2.1 \%$ of all pediatric NHLs. In previous studies, ALCLs accounted for $15 \%$ of pediatric NHLs in the UK (23), $11.5 \%$ in India (19), $10.3 \%$ in Germany (24) and $20.5 \%$ in Korea (28). However, the possible reasons of geographic differences in the spectrum of lymphoma remain unknown, mainly due to the etiology of lymphoma being largely unknown, although certain risk factors were recently documented, including genetic factors, immune abnormalities, individual susceptibility, lifestyle, environmental exposures, as well as various infections caused by bacteria, viruses, mycoplasma and chlamydia (30). Epidemiologic studies suggested that 
the distribution of lymphoma subtypes exhibits significant geographic variation (31). However, research regarding such information in Egypt is limited.

NHL in children is generally considered to be widely disseminated from the outset, even when apparently localized (32). In the present study, $88.7 \%$ of NHL patients had Murphy stage III/IV disease and only $11.3 \%$ had stage I/II disease; similar results were reported by several previous studies $(1,14,29,33)$. The high prevalence rates of advanced tumor stage in our series was possibly associated with, among other factors, the large number of patients with voluminous abdominal lymphomas, late diagnosis and the predominance of primary mediastinal tumors within the lymphoblastic histological type, and with the low frequency of NHL with more superficial primary sites, such as tumors of the head neck and primary nodal disease, making it difficult to detect the disease at an earlier stage.

Tumors in pediatric NHL cases are frequently found extranodally and are difficult to diagnose, clinically as well as histopathologically $(14,34,35)$. In our analysis of 142 patients with NHL, abdominal involvement was the most common presentation $(73.2 \%)$, followed by mediastinal involvement, while bone marrow infiltration was the most common site of metastasis; similar results was reported by many authors $(21,36)$. In Turkey, abdominal involvement was the most common presentation $(>75 \%)$, followed by the jaw and the central nervous system (21). As regards identifying prognostic factors, no statistically significant associations were observed between age, gender, histopathology and staging and either OS or EFS in our study. The 5-year OS and EFS in the present study were 88.7 and $85.1 \%$, respectively (Figs. 1 and 2). The survival of our patients is consistent with the results presented by the major collaborative childhood cancer treatment groups, reporting a survival rate of $\sim 80-90 \%$ for patients with NHL (37-41).

In conclusion, NHL occurs at younger age among pediatric patients in Egypt, with a higher incidence of BL and advanced-stage disease. The outcome of NHL in our two centers was satisfactory, approaching the international rates.

\section{References}

1. Sandlund JT, Downing JR and Crist WM: Non-Hodgkin's lymphoma in childhood. N Engl J Med 334: 1238-1248, 1996.

2. Cairo MS, Raetz E, Lim MS, et al: Childhood and adolescent non-Hodgkin lymphoma: new insights in biology and critical challenges for the future. Pediatr Blood Cancer 45: 753-769, 2005

3. Gross TG and Termuhlen AM: Pediatric non-Hodgkin's lymphoma. Curr Oncol Rep 9: 459-465, 2007.

4. Hochberg J, Waxman IM, Kelly KM, et al: Adolescent non-Hodgkin lymphoma and Hodgkin lymphoma: state of the science. Br J Haematol 144: 24-40, 2009.

5. Brousse N, Vasiliu V, Michon J, et al: Pediatric non-Hodgkin lymphomas. Ann Pathol 24: 574-586, 2004 (In French).

6. Setty BA and Termuhlen AM: Rare pediatric non-Hodgkin lymphoma. Curr Hematol Malig Rep 5: 163-168, 2010.

7. Sharon V, Mecca PS, Steinherz PG, et al: Two pediatric cases of primary cutaneous B-cell lymphoma and review of the literature. Pediatr Dermatol 26: 34-39, 2009.

8. Swerdlow SH: Pediatric follicular lymphomas, marginal zone lymphomas, and marginal zone hyperplasia. Am J Clin Pathol 122 (Suppl): S98-S109, 2004.

9. Lones MA, Perkins SL, Sposto R, et al: Non-Hodgkin lymphoma arising in bone in children and adolescents is associated with an excellent outcome: a Children's Cancer Group Report. J Clin Oncol 20: 2293-2301, 2002.
10. Gatta G, Corazziari I, Magnani C, Peris-Bonet R, Roazzi P, Stiller C; EUROCARE Working Group: Childhood cancer survival in Europe. Ann Oncol 14 (Suppl 5): v119-v127, 2003.

11. Gross TG and Perkins SL: Malignant non-Hodgkin's lymphoma in children. In: Principles and Practice of Pediatric Oncology. Pizzo PA and Poplack DG (eds). 6th edition. Lippincott Williams, Philadelphia, pp663-682, 2011.

12. Gutierrez MI, Bhatia K, Barriga F, et al: Molecular epidemiology of Burkitt's lymphoma from South America: differences in breakpoint location and Epstein-Barr virus association from tumors in other world regions. Blood 79: 3261-3266, 1992.

13. Jaffe ES, Harris NL, Stein H, et al: Introduction and overview of the classification of the lymphoid neoplasms. In: WHO Classification of Tumours of Haematopoietic and Lymphoid Tissues. Swerdlow SH, Campo E, Harris NL, Jaffe ES, Pileri SA, Stein H, Thiele J and Vardiman JW (eds). 4th edition. IARC Press, Lyon, pp157-166, 2008.

14. Murphy SB: Classification, staging and end results of treatment of childhood non-Hodgkin's lymphomas: dissimilarities from lymphomas in adults. Semin Oncol 7: 332-339, 1980.

15. Ries LAG, Smith MA, Gurney JG, Linet M, Tamra T, Young JL and Bruin GR (eds): Cancer Incidence and Survival Among Children and Adolescents: United States SEER Program 1975-1995. National Cancer Institute, SEER Program, NIH publication no. 99-4649, Bethesda, MD, 1999.

16. Pedrosa MF, Pedrosa F, Lins MM, et al: Non-Hodgkin's lymphoma in childhood: clinical and epidemiological characteristics and survival analysis at a single center in Northeast Brazil. J Pediatr (Rio J) 83: 547-554, 2007.

17. Sandlund JT, Fonseca T, Leimig T, et al: Predominance and characteristics of Burkitt lymphoma among children with non-Hodgkin lymphoma in northeastern Brazil. Leukemia 11: 743-756, 1997.

18. Klumb CE, Schramm MT, De Resende LM, et al: Treatment of children with B-cell non-Hodgkin's lymphoma in developing countries: the experience of a single center in Brazil. J Pediatr Hematol Oncol 26: 462-468, 2004.

19. Manipadam MT, Nair S, Viswabandya A, et al: Non-Hodgkin lymphoma in childhood and adolescence: frequency and distribution of immunomorphological types from a tertiary care center in South India. World J Pediatr 7: 318-325, 2011.

20. Harris NL, Jaffe ES, Diebold J, et al: Word Health Organization classification of neoplastic disease of the hematopoietic and lymphoid tissues: report of the Clinical Advisory Committee meeting-Airlie House, Virginia, November 1997. J Clin Oncol 17: 3835-3849, 1999.

21. Naresh KN, Agarwal B, Nathwani BN, et al: Use of the World Health Organization (WHO) classification of non-Hodgkin's lymphoma in Mumbai, India: a review of 200 consecutive cases by a panel of five expert hematopathologists. Leuk Lymphoma 45: 1569-1577, 2004.

22. Temmim L, Baker H, Amanguno H, et al: Clinicopathological features of extranodal lymphomas: Kuwait experience. Oncology 67: 382-389, 2004.

23. Wright D, McKeever P and Carter R: Childhood non-Hodgkin lymphomas in the United Kingdom: findings from the UK Children's Cancer Study Group. J Clin Pathol 50: 128-134, 1997.

24. Burkhardt B, Zimmermann M, Oschlies I, et al; BFM Group: The impact of age and gender on biology, clinical features and treatment outcome of non-Hodgkin lymphoma in childhood and adolescence. Br J Haematol 131: 39-49, 2005.

25. Mokhtar N and Khaled H: Lymphoma. 1st edition. Aventis Oncol, Cairo, pp47-63, 123-134, 2002.

26. Srinivas V, Soman CS and Naresh KN: Study of the distribution of 289 non-Hodgkin lymphomas using the WHO classification among children and adolescents in India. Med Pediatr Oncol 39: 40-43, 2002.

27. Magrath IT: African Burkitt's lymphoma. History, biology, clinical features, and treatment. Am J Pediatr Hematol Oncol 13: 222-246, 1991

28. Hwang IG, Yoo KH, Lee SH, et al: Clinicopathologic features and treatment outcomes in malignant lymphoma of pediatric and young adult patients in Korea: comparison of Korean all-ages group and Western younger age group. Clin Lymphoma Myeloma 7: 580-586, 2007.

29. Nakagawa A, Nakamura S, Nakamine H, et al: Pathology review for paediatric non-Hodgkin's lymphoma patients in Japan; a report from the Japan association of childhood leukemia study (JACLS). Eur J Cancer 40: 725-733, 2004. 
30. Jaffe ES, Harris NL, Stein H and Vardiman JW (eds): Pathology and genetics of tumours of haematopoietic and lymphoid tissues. In: World Health Organization Classification of Tumours. 3rd edition. IARC Press, Lyon, pp227-230, 2001.

31. Anderson JR, Armitage JO and Weisenburger DD: Epidemiology of the non-Hodgkin's lymphomas: distributions of the major subtypes differ by geographic locations. Non-Hodgkin's Lymphoma Classification Project. Ann Oncol 9: 717-720, 1998

32. Patte C: Non-Hodgkin's lymphoma. Eur J Cancer 34: 359-363, 1998.

33. Boerma EG, van Imhoff GW, Appel IM, et al: Gender and age-related difference in Burkitt lymphoma - epidemiological and clinical data from The Netherlands. Eur J Cancer 40: 2781-2787, 2004

34. Pinkerton CR: The continuing challenge of treatment for non-Hodgkin's lymphoma in children. Br J Haematol 107: 220-234, 1999.

35. Perkins SL: Work-up and diagnosis of pediatric non-Hodkin's lymphomas. Pediatr Dev Pathol 3: 374-390, 2000.

36. Temmim L, Baker H, Al-Jarallah M, et al: Clinical characteristics and pathological classification of non-Hodgkin's lymphoma in Kuwait. Results of a collaborative study with the International Lymphoma Study Group (ILSG). Leuk Lymphoma 45: 1865-1871, 2004.
37. Reiter A, Schrappe M, Parwaresch R, et al: Non-Hodgkin's lymphomas of childhood and adolescence: results of a treatment stratified for biologic subtypes and stage - a report of Berlin-Frankfurt-Münster Group. J Clin Oncol 13: 359-372, 1995.

38. Reiter A, Schrappe M, Ludwig WD, et al: Intensive ALL-type therapy without local radiotherapy provides a $90 \%$ event-free survival for children with T-cell lymphoblastic lymphoma: a BFM group report. Blood 95: 416-421, 2000.

39. Link MP, Shuster JJ, Donaldson SS, et al: Treatment of children and young adults with early-stage non-Hodgkin's lymphoma. N Engl J Med 337: 1259-1266, 1997.

40. Seidemann K, Tiemann M, Schrappe M, et al: Short-pulse B-non-Hodgkin lymphoma-type chemotherapy is efficacious treatment for pediatric anaplastic large cell lymphoma: a report of the Berlin-Frankfurt-Munster Group Trial NHL-BFM 90. Blood 97: 3699-3706, 2001.

41. Laver JH, Kraveka JM, Hutchison RE, et al: Advanced-stage large-cell lymphoma in children and adolescents: results of a randomized trial incorporating intermediate-dose methotrexate and high-dose cytarabine in the maintenance phase of the APO regimen: a Pediatric Oncology Group phase III trial. J Clin Oncol 23: 541-547, 2005. 